\title{
Lodo de esgoto como fonte de nitrogênio: concentração no perfil do solo e em plantas de milho
}

\section{Sewage sludge as source of nitrogen: concentration in the soil profile and in corn plants}

\author{
Fernando Giovannetti de Macedo \\ Doutorando em Ciências (Química na agricultura e Meio ambiente) pelo Centro de Energia Nuclear na Agricultura da Universidade de São Paulo \\ (CENA/USP) - Piracicaba (SP), Brasil.
}

\section{Wanderley José de Melo}

Doutor em Solos e Nutrição de Plantas pela USP. Professor Titular do Departamento de Tecnologia da Universidade Estadual Paulista (UNESP) - Jaboticabal (SP), Brasil.

\section{Luciana Cristina Souza Merlino}

Doutoranda em Produção Vegetal pela UNESP - Jaboticabal (SP), Brasil.

\section{Luma Stefânia Torres}

Mestranda em Produção Vegetal pela UNESP - Jaboticabal (SP), Brasil.

\section{Ana Carolina Trisltz Perassolo Guedes}

Mestranda em Produção Vegetal pela UNESP - Jaboticabal (SP), Brasil.

\section{Gabriel Mauricio Peruca de Melo}

Doutor em Zootecnia pela UNESP. Professor da Universidade Camilo Castelo Branco (UNICASTELO) - Descalvado (SP), Brasil.

\section{Marcos Antônio Camacho}

Doutor em Produção Vegetal pela UNESP. Professor do Departamento de Solos da Universidade Estadual de Mato Grosso do Sul (UEMS) - Aquidauana

(MS), Brasil.

\section{Resumo}

O objetivo deste trabalho foi avaliar a concentração de nitrogênio em plantas de milho e ao longo do perfil de um Latossolo Vermelho eutroférrico submetido a doses de lodo de esgoto e fertilizante mineral. O experimento foi instalado em delineamento experimental em blocos casualizados com 4 tratamentos (0,0; 55,0; 110,0 e 167,5 Mg.ha-1 de lodo de esgoto em doses acumuladas) e 5 repetições para um período de avaliação de 1 ano. A amostragem de solo foi realizada aos 60 dias após a emergência (d.a.e.) das plantas nas profundidades $0,0-0,1,0,1-0,2,0,2-0,4,0,4-0,6,0,6-0,8$ e 0,8-1,0 m. Também aos 60 , 80 e 128 d.a.e. foram coletadas, respectivamente, folha diagnose, planta inteira e grão. As maiores doses de lodo de esgoto proporcionaram maiores quantidades de nitrogênio no solo. O nitrogênio do solo, após a profundidade de 0,6 m, não diferiu entre as camadas avaliadas. Quanto maior a dose de lodo de esgoto, menor a proporção de nitrogênio em profundidade.

Palavras-chave: adubo orgânico; biossólidos; poluição ambiental.

\begin{abstract}
The aim of this study was to evaluate the concentration of nitrogen in corn plants and along the profile of an Oxisol subjected to doses of sewage sludge and mineral fertilizer. The experiment was conducted in randomized complete block design with 4 treatments $(0.0 ; 55.0 ; 110.0$ and $167.5 \mathrm{Mg}$.ha-1 of sewage sludge accumulated doses) and 5 reps for a trial period of 1 year. Soil sampling was performed 60 days after emergence (d.a.e.) plants at depths $0-0.1,0.1-0.2$, $0.2-0.4,0.4-0.6,0.6-0.8$ and $0.8-1.0 \mathrm{~m}$. Also at 60,80 and 128 d.a.e. were collected, respectively, diagnosis leaf, whole plant and grain. Higher doses of sewage sludge provided higher amounts of nitrogen in the soil. The soil nitrogen, after the depth of $0.6 \mathrm{~m}$, did not differ between the layers evaluated. The higher the dose of sewage sludge, the lower the proportion of nitrogen in depth.
\end{abstract}

Keywords: organic fertilizer; biossolids; environmental pollution. 


\section{Introdução}

O Nitrogênio (N) é o nutriente exigido em maior quantidade pela maioria das espécies vegetais e faz parte de várias estruturas nas plantas superiores, podendo ser absorvido como cátion $\left(\mathrm{NH}_{4}^{+}\right)$ou ânion $\left(\mathrm{NO}_{3}^{-}\right.$) (EPSTEIN \& BLOOM, 2004), estando sujeito a diversas reações no solo (MALAVOLTA, 2006).

No mundo, calcula-se que a eficiência de seu uso em cereais seja de apenas 33\% (RAUN \& JOHNSON, 1999) e que o seu custo é o mais elevado dentre os nutrientes utilizados na adubação. Consequentemente, ele é o elemento com maior número de pesquisas no que se refere à nutrição de plantas, bem como à dinâmica no solo, com ênfase para as perdas das formas nitrogenadas iônicas (HANSEN et al., 2000; MANTOVANI et al., 2007).

$\mathrm{O} \mathrm{NO}_{3}{ }^{-}$é a forma mineral de nitrogênio predominante nos solos sem restrição de oxigênio. Devido ao predomínio de cargas negativas na camada arável dos solos tropicais, a sua adsorção eletrostática é insignificante. Desta forma, o nitrato permanece na solução do solo, o que favorece a sua lixiviação no perfil para profundidades inexploradas pelas raízes (CERETTA \& FRIES, 1997), sendo esta a principal forma de perda do nitrogênio no solo (WARD et al., 2007).

A movimentação descendente do nitrato não é desejável abaixo da zona das raízes, pois, além dele não ser absorvido pelas plantas, pode contaminar as águas subterrâneas (BROUSSARD \& TURNER, 2009).

Araújo et al. (2011) lembram que as águas subterrâneas, por se encontrarem total ou parcialmente confinadas, são geralmente mais protegidas da poluição que as superficiais devido à presença do solo atuando como meio filtrante. Quando estas águas se tornam poluídas e se concentram num aquífero, este, por estar mais protegido, é também mais difícil de ser recuperado, pois não está sujeito aos processos de autodepuração comuns aos sistemas livres, tais como fotodecomposição, ampla oxigenação, transformações microbianas aeróbicas, etc.

$\mathrm{O}$ aumento da concentração de $\mathrm{NO}_{3}{ }^{-}$na água tem gerado grande discussão sobre os seus efeitos na saúde e no ambiente, estimulando pesquisas de caráter agroecológico no mundo inteiro, principalmente em países da Europa e da América do Norte (FABIANOVICZ \& SILVA JUNIOR, 2007; ANDRASKI; BUNDY; BRYE, 2000).

Neste sentido, fontes alternativas, como os adubos orgânicos, são apontadas como formas de minimizar as perdas de nitrogênio por lixiviação e, consequentemente, reduzir a contaminação dos lençóis freáticos. Isto porque os adubos orgânicos disponibilizam os nutrientes gradativamente, à medida que são mineralizados. Piovesan et al. (2009) preconizam este processo como uma forma de ajustar a adubação nitrogenada. Outro fator relevante é determinar a concentração do nutriente na planta para avaliar o estado nutricional da cultura.

O lodo de esgoto, em consequência de sua riqueza em nutrientes, principalmente nitrogênio, tem sido utilizado em muitos países como fertilizante (BINDER et al., 2002), porém, Paula et al. (2011) questionam o uso de doses excessivas, que podem contaminar o lençol freático.
Ao contrário dos aspectos relacionados a metais pesados, o potencial de lixiviação de nitrogênio, proveniente da aplicação de lodo de esgoto em áreas agrícolas, não tem sido avaliado nos solos do Brasil (OLIVEIRA et al., 2001). Esses estudos devem ser executados preferencialmente em condições de campo, por longos períodos e por equipes multidisciplinares (BETTIOL \& CAMARGO, 2007).

O presente trabalho teve por objetivo quantificar a concentração de nitrogênio proveniente de doses de lodo de esgoto e adubo mineral em plantas de milho e em diferentes profundidades do solo.

\section{Metodologia}

O experimento foi inicialmente instalado em novembro de 1997 e vem sendo conduzido na área experimental da Faculdade de Ciências Agrárias e Veterinárias da Universidade Estadual Paulista Júlio de Mesquita Filho (UNESP), Campus de Jaboticabal, em São Paulo. localizada a uma altitude de $610 \mathrm{~m}$ e com as coordenadas geográficas: $21^{\circ} 15^{\prime} 22^{\prime \prime}$ S e 48 $15^{\prime} 18^{\prime \prime}$ W. O clima é do tipo Cwa, segundo classificação de Köppen.

A área possui um Latossolo Vermelho eutroférrico, textura argilosa, A moderado caulinítico (EMBRAPA, 2006). O delineamento experimental utilizado foi em blocos casualizados, com 4 tratamentos e 5 repetições, sendo o tamanho das parcelas de $60 \mathrm{~m}^{2}$ (6x10 m). Os tratamentos inicialmente utilizados foram: testemunha (sem fertilização);

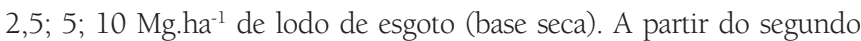
ano, optou-se por adubar o tratamento testemunha de acordo com a análise de fertilidade do solo e as indicações contidas em estudo de Raij e Cantarella (1997). Após o $3^{\circ}$ ano, com base nos resultados até então obtidos, e na tentativa de provocar fitotoxidade por metais pesados,

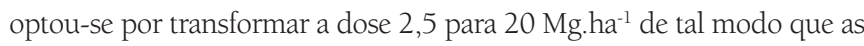
doses acumuladas no $11^{\circ}$ ano foram 0, 55, 110 e 167,5. Mg.ha-1 de lodo de esgoto base seca (Tabela 1). As doses de 5, 10 e $20 \mathrm{Mg} \cdot$ ha $^{-1}$ proporcionaram respectivamente 167,1; 334,2 e 668,4 kg.ha-1 de N.

Levando em conta a Resolução 375 (BRASIL, 2006) de recomendação de aplicação agrícola de lodo de esgoto, admitiu-se que

Tabela 1 - Tratamentos utilizados durante os 11 anos do experimento.

\begin{tabular}{lcccc} 
& \multicolumn{4}{c}{ Tratamentos } \\
\cline { 3 - 5 } Ano & Testemunha & \multicolumn{3}{c}{ Lodo de esgoto Mg.ha ${ }^{-1}$} \\
\cline { 3 - 5 } & & $55^{*}$ & $110^{*}$ & $167,5^{*}$ \\
\hline $1997 / 98$ & sem fertilização & 5 & 10 & 2,5 \\
\hline $1998 / 99$ & fertilizante mineral & 5 & 10 & 2,5 \\
\hline $1999 / 00$ & fertilizante mineral & 5 & 10 & 2,5 \\
\hline $2000 / 01$ & fertilizante mineral & 5 & 10 & 20,0 \\
\hline $2001 / 02$ & fertilizante mineral & 5 & 10 & 20,0 \\
\hline $2002 / 03$ & fertilizante mineral & 5 & 10 & 20,0 \\
\hline $2003 / 04$ & fertilizante mineral & 5 & 10 & 20,0 \\
\hline $2004 / 05$ & fertilizante mineral & 5 & 10 & 20,0 \\
\hline $2005 / 06$ & fertilizante mineral & 5 & 10 & 20,0 \\
\hline $2006 / 07$ & fertilizante mineral & 5 & 10 & 20,0 \\
\hline
\end{tabular}

*Doses acumuladas de lodo de esgoto em 11 anos de experimentação. 
um terço do nitrogênio contido no resíduo estaria disponível para as plantas. Para as doses de lodo de esgoto em que 1/3 do nitrogênio contido não supria a necessidade da cultura $-170 \mathrm{~kg}$.ha-1 ${ }^{-1}$, sendo $30 \mathrm{~kg}$ na semeadura e o restante em cobertura —, utilizou-se uma fonte mineral (sulfato de amônio) aplicada em cobertura.

O lodo de esgoto foi obtido junto à Estação de Tratamento de Esgoto (ETE) da SABESP, localizada em Franca, interior paulistano. Para a caracterização química do lodo de esgoto (Tabela 2) coletaram-se seis amostras simples em diferentes pontos da massa do resíduo, as quais foram homogeneizadas e reunidas em uma amostra composta.

O milho foi a cultura utilizada ao longo do experimento, sendo que no sétimo ano optou-se pelo girassol e no oitavo pela crotalária, visando a rotação de cultura, uma vez que a produtividade da cultura do milho vinha decrescendo com o tempo em todos os tratamentos.

A amostragem do solo para fins de avaliação da fertilidade (Tabela 3) foi realizada seguindo métodos preconizados por Raij et al. (2001).

O lodo de esgoto, nas parcelas que o receberam, foi aplicado a lanço, em área total, uniformemente distribuído, nas respectivas doses de cada tratamento, com a umidade com que chegou da ETE (73\%), sendo incorporado por meio de gradagem leve (10 $\mathrm{cm}$ de profundidade)

Passada uma semana da aplicação do lodo de esgoto, a cultura foi semeada e quando as plântulas apresentavam cerca de $20 \mathrm{~cm}$ de altura foi realizado desbaste, deixando-se 5-7 plantas metro linear. Para todas as coletas foram utilizadas apenas as quatro linhas centrais de cada parcela, sendo as duas das extremidades consideradas bordaduras.

O híbrido de milho no décimo primeiro ano foi a Dekalb 390, considerada super precoce e de alta produtividade.

Para avaliação do N, a amostragem de solo foi realizada aos 60 dias após a emergência (d.a.e.), sendo coletadas 10 subamostras por parcela (5 na linha de plantio a $5 \mathrm{~cm}$ das plantas e 5 nas entrelinhas), nas profundidades de $0,0-0,1 ; 0,1-0,2 ; 0,2-0,4 ; 0,4-0,6 ; 0,6-0,8$ e 0,8-1,0 m.
Também aos 60, 80 e 128 d.a.e. foram coletadas, respectivamente, folha diagnose (RAIJ et al., 1997), planta inteira e grãos.

O teor de $\mathrm{N}_{\text {kjeldahl }}$ nas amostras de solo foi determinado conforme o método descrito em Melo (1974), que consiste em oxidar o N-orgânico a $\mathrm{N}$ amoniacal pelo ácido sulfúrico em presença de catalisadores e elevadores de temperatura. $\mathrm{O} \mathrm{N}$ amoniacal produzido foi determinado por destilação a vapor. Para avaliação do nível crítico de N nas folhas diagnose utilizou-se padrão proposto por Malavolta et al. (1997).

Foi calculada a porcentagem relativa de nitrogênio em camadas subsuperficiais para cada dose, nas quais se considerou hipoteticamente o nitrogênio da primeira camada de cada tratamento como $100 \%$, sendo os valores das demais proporcionais a este.

Os resultados foram submetidos à análise de variância e houve aplicação do teste de Tukey, a 5\% de probabilidade e em parcelas subdivididas para solo, e regressão para folha diagnose, planta inteira e grãos. Para tanto, foi utilizado o programa Assistat (SILVA \& AZEVEDO, 2002).

\section{Resultados}

A dose acumulada de lodo de esgoto que proporcionou maior quantidade de nitrogênio no solo foi a de $167,5 \mathrm{Mg} \cdot \mathrm{ha}^{-1}$. A maior concentração de nitrogênio se deu na camada mais superficial do solo (0-0,1 m), onde a testemunha e a dose de 55,0 Mg.ha ${ }^{-1}$ foram semelhantes, assim como as doses 110,0 e 167,5 Mg.ha-1 também não diferiram entre si, sendo estas últimas as que apresentaram maior concentração do elemento (Tabela 4). A quantidade de nitrogênio fornecida pelos tratamentos, justifica este efeito.

Avaliando-se as profundidades do solo, no tratamento testemunha, verifica-se que o nitrogênio apresenta-se com dependência espacial, observando maiores teores de nitrogênio na camada superficial $(0-0,1 \mathrm{~m})$. Em seguida, ele tende a diminuir até a profundidade de 0,2-0,4 m, quando volta a elevar-se na profundidade 0,4-0,6 m,

Tabela 2 - Caracterização química do lodo de esgoto usado no $11^{\circ}$ ano de experimentação.

\begin{tabular}{|c|c|c|c|c|c|c|c|c|c|c|c|}
\hline \multicolumn{2}{|c|}{$\mathrm{N}$} & \multicolumn{2}{|c|}{$P$} & \multicolumn{2}{|c|}{$\mathrm{K}$} & \multicolumn{2}{|c|}{$\mathrm{Ca}$} & \multicolumn{2}{|c|}{$\mathrm{Mg}$} & \multicolumn{2}{|c|}{ S } \\
\hline \multicolumn{12}{|c|}{ g. $\mathrm{kg}^{-1}$} \\
\hline \multicolumn{2}{|c|}{33,42} & \multicolumn{2}{|c|}{38,23} & \multicolumn{2}{|c|}{1,50} & \multicolumn{2}{|c|}{25,20} & \multicolumn{2}{|c|}{3,52} & \multicolumn{2}{|c|}{5,28} \\
\hline $\mathrm{Cu}$ & $\mathrm{Fe}$ & $\mathrm{Mn}$ & $\mathrm{Zn}$ & B & Mo & $\mathrm{Cr}$ & $\mathrm{Cd}$ & $\mathrm{Ni}$ & $\mathrm{Pb}$ & $\mathrm{Ba}$ & Co \\
\hline \multicolumn{12}{|c|}{$\mathrm{mg} \cdot \mathrm{kg}^{-1}$} \\
\hline \multirow[t]{2}{*}{572,55} & $184.100,00$ & 726,99 & $1.028,30$ & 71,65 & 2,77 & 284,46 & 3,27 & 56,63 & 77,28 & 306,55 & 29,04 \\
\hline & & & & & & $1.000 *$ & $39 *$ & & $300 *$ & & \\
\hline
\end{tabular}

*Concentração máxima permitida de metais pesados no lodo de esgoto para uso agrícola conforme normas do CONAMA (2006).

Tabela 3 - Caracterização química do latossolo vermelho eutroférrico $(0-0,2 \mathrm{~m})$ antes da instalação do experimento no $11^{\circ}$ ano agrícola (2007/2008).

\begin{tabular}{|c|c|c|c|c|c|c|c|c|c|c|}
\hline Tratamentos & $\mathrm{pH}$ & M.O. & $P_{\text {resina }}$ & $\mathrm{K}$ & $\mathrm{Ca}$ & $\mathrm{Mg}$ & $\mathrm{H}+\mathrm{Al}$ & SB & $\mathrm{T}$ & V \\
\hline Mg.ha-1 LE & $\mathrm{CaCl}_{2}$ & g. dm ${ }^{-3}$ & $\mathrm{mg} \cdot \mathrm{dm}^{-3}$ & \multicolumn{6}{|c|}{$\mathrm{mmol}_{\mathrm{c}} \cdot \mathrm{dm}^{-3}$} & $\%$ \\
\hline 0,0 & 5,0 & 27 & 49 & 4,5 & 27 & 6 & 38 & 37,5 & 75,5 & 50 \\
\hline 55,0 & 5,1 & 27 & 50 & 2,8 & 33 & 8 & 34 & 43,8 & 77,8 & 56 \\
\hline 110,0 & 5,2 & 30 & 87 & 3,0 & 40 & 9 & 34 & 52,0 & 86,0 & 60 \\
\hline 167,5 & 4,7 & 31 & 107 & 1,8 & 33 & 7 & 58 & 41,8 & 99,8 & 42 \\
\hline
\end{tabular}

LE: lodo de esgoto, base seca, em doses acumuladas nos 11 anos de aplicação do resíduo. 
apresentando concentração semelhante à da profundidade 0,1-0,2 m e superior a 0,2-0,4 m. Na sequência, volta a diminuir (Figura 1). Para os tratamentos com lodo de esgoto observa-se perfil relativamente homogêneo a partir da camada $0,1-0,2 \mathrm{~m}$, onde houve redução na concentração de nitrogênio com o aumento da profundidade.

A Tabela 5 indica a porcentagem de nitrogênio ao longo do perfil do solo em relação à quantidade determinada na primeira camada $(0-0,1 \mathrm{~m})$ de cada tratamento. Embora os dados expressem valores absolutos, observa-se que o testemunha e 55,0 Mg.ha-1 apresentam maior porcentagem de perda em relação à camada superficial se comparados aos outros tratamentos.

Quanto à avaliação do estado nutricional das plantas de milho, os valores referentes à planta inteira, folha diagnose e grão (Figura 2) não foram influenciados pelos tratamentos testados, porém, os teores de nitrogênio encontrados na folha diagnose superam a faixa ideal (27,5 a 32,5 g.kg) de acordo com Malavolta, Vitti e Oliveira (1997).

\section{Discussão}

A maior concentração de nitrogênio na camada superficial do solo (0-0,1 m) se deve principalmente à matéria orgânica que se acumula nessa região devido aos restos culturais que ficam sobre o solo de um ano para o outro e, no caso dos tratamentos com lodo de esgoto, soma-se a isso o efeito da matéria orgânica adicionada com o uso de tal resíduo, justamente incorporado à profundidade de 0-0,1 m (Tabela 4).

Quanto à oscilação do nitrogênio ao longo do perfil do solo, apesar dessa elevação significativa da concentração do elemento na camada 0,4-0,6 m no tratamento testemunha em relação à profundidade 0,2-0,4 m, não é possível afirmar que o aumento na profundidade possa interferir na nutrição das plantas, já que a maioria absoluta do nitrogênio permaneceu na camada superficial $(0-0,1 \mathrm{~m})$.

A causa da variação em profundidade pode ter influência de diversos fatores, com destaque para a capacidade de absorção do elemento pela cultura, velocidade de mineralização do nitrogênio, tipo de solo e quantidade e velocidade de infiltração de água no solo.

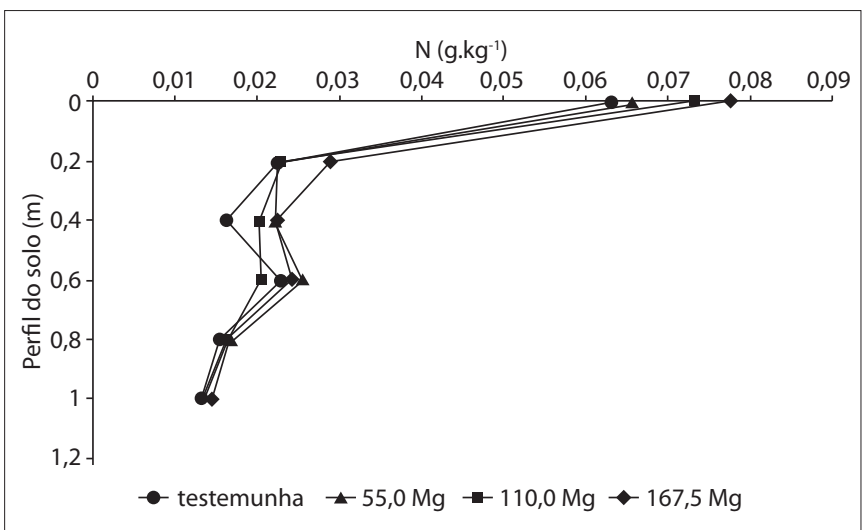

Figura 1 - Concentração de nitrogênio dos tratamentos avaliados ao longo do perfil de um solo tratado com lodo de esgoto por 11 anos.
O efeito de grandes aumentos na concentração de nutrientes em profundidades superiores a 0,4 m não é desejado para a maioria das culturas anuais, pelo fato de que tais plantas exploram apenas as primeiras camadas do solo, em geral até 0,4 $\mathrm{m}$ de profundidade. Com isso, todo nitrogênio que se encontra em camadas abaixo desta

Tabela 4 - Concentração de nitrogênio ao longo do perfil de um solo tratado com lodo de esgoto por 11 anos.

\begin{tabular}{|c|c|c|c|c|}
\hline $\begin{array}{l}\text { Camada } \\
\text { do solo }\end{array}$ & Testemunha & $\begin{array}{c}55,0 \mathrm{Mg} \\
\mathrm{ha}^{-1}\end{array}$ & $\begin{array}{c}\text { LE } \\
110,0 \mathrm{Mg} \text {. } \\
\text { ha }^{-1}\end{array}$ & $\begin{array}{c}167,5 \mathrm{Mg} . \\
\mathrm{ha}^{-1}\end{array}$ \\
\hline (m) & \multicolumn{4}{|c|}{$\mathrm{N}_{\text {kjeldahl }}\left(\mathrm{g} \cdot \mathrm{kg}^{-1}\right)$} \\
\hline $0,0-0,1$ & $0,0632 \mathrm{bA}$ & $0,0656 \mathrm{bA}$ & $0,0733 a A$ & $0,0777 \mathrm{aA}$ \\
\hline $0,1-0,2$ & $0,0225 \mathrm{bB}$ & $0,0225 \mathrm{bB}$ & $0,0229 \mathrm{bB}$ & $0,0290 \mathrm{aB}$ \\
\hline $0,2-0,4$ & $0,0163 \mathrm{bC}$ & $0,0221 \mathrm{aB}$ & $0,0202 \mathrm{abBC}$ & $0,0225 \mathrm{aC}$ \\
\hline $0,4-0,6$ & $0,0227 \mathrm{abB}$ & $0,0225 \mathrm{aB}$ & $0,0207 \mathrm{bC}$ & $0,0243 \mathrm{aBC}$ \\
\hline $0,6-0,8$ & $0,0154 \mathrm{aC}$ & $0,0168 \mathrm{aCD}$ & $0,0167 \mathrm{aCD}$ & $0,0163 \mathrm{aD}$ \\
\hline $0,8-1,0$ & $0,0132 \mathrm{aC}$ & $0,0136 \mathrm{aC}$ & $0,0134 a D$ & $0,0144 \mathrm{aD}$ \\
\hline
\end{tabular}

LE: lodo de esgoto, base seca, em doses acumuladas nos 11 anos de aplicação do resíduo. Parcelas (doses de lodo de esgoto, $\mathrm{CV}=12,67 \%$ ) e subparcelas (profundidades,

$\mathrm{CV}=9,55 \%$ ). Médias seguidas de mesma letra maiúscula para profundidades (na vertical) e de mesma letra minúscula para tratamentos (na horizontal) não diferem entre si pelo Teste de Tukey, ao nível de $5 \%$ de probabilidade.

Tabela 5 - Porcentagem de nitrogênio das camadas subsuperficiais de cada tratamento em relação à quantidade determinada na primeira camada $(0-0,1)$ de um solo tratado com lodo de esgoto por 11 anos.

\begin{tabular}{lcccc} 
Profundidade & \multicolumn{4}{c}{ LE Mg.ha- $^{-1}$} \\
\cline { 2 - 5 }$(\mathrm{m})$ & Testemunha & 55,0 & 110,0 & 167,5 \\
\hline $0,0-0,1$ & 100,0 & 100,0 & 100,0 & 100,0 \\
\hline $0,1-0,2$ & 35,6 & 34,3 & 31,3 & 37,3 \\
\hline $0,2-0,4$ & 25,8 & 33,7 & 27,6 & 29,0 \\
$0,4-0,6$ & 35,9 & 38,9 & 28,2 & 31,3 \\
\hline $0,6-0,8$ & 24,4 & 25,6 & 22,8 & 21,0 \\
\hline $0,8-1,0$ & 20,9 & 20,7 & 18,3 & 18,5 \\
\hline
\end{tabular}

LE: lodo de esgoto, base seca, em doses acumuladas nos 11 anos de aplicação do resíduo.

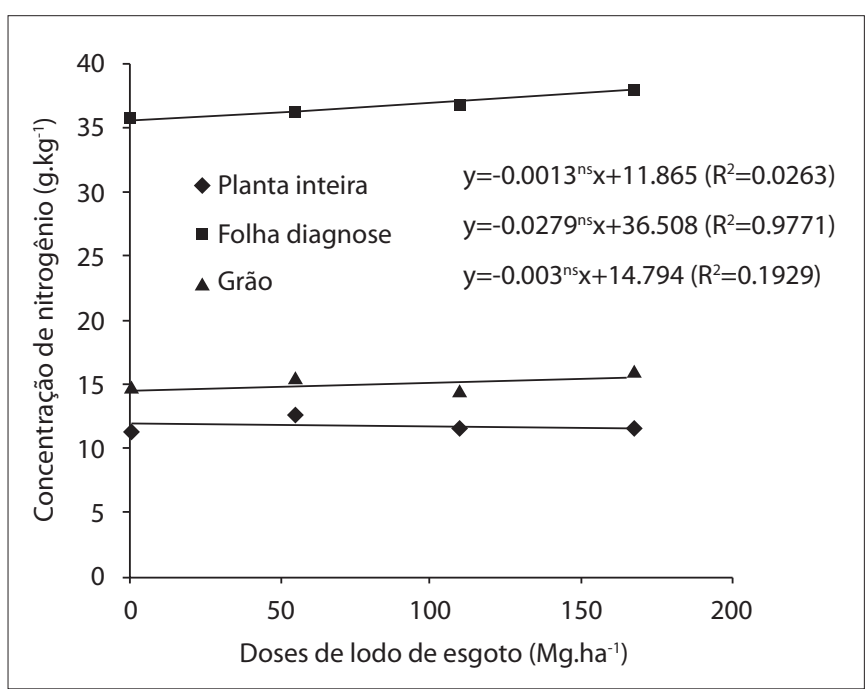

Figura 2 - Concentração de nitrogênio na planta inteira, folha diagnose e grão de milho adubado com lodo de esgoto. 
profundidade não é mais usado pelas culturas e torna-se passível de contaminar os lençóis freáticos. Stintzing e Salomon (2002) avaliaram diversas doses e fontes de nitrogênio ao longo do perfil do solo e verificaram efeito semelhante apenas quando utilizaram uma dose elevada (600 kg.ha-1) de nitrogênio mineral.

Também somando os valores percentuais das três últimas camadas de cada tratamento (Tabela 5), que correspondem à profundidade onde as raízes não mais exploram, verifica-se que a quantidade de perda de nitrogênio do testemunha e 55,0.Mg ha-1 se assemelham (81,2 e 85,2\%, respectivamente) e superam os valores encontrados nos tratamentos 110,0 e 165,7 Mg.ha-1 , que também se assemelham (69,3 e 70,8\%).

Neste sentido, podemos atribuir as maiores perdas por nitrogênio à fonte mineral aplicada, uma vez que o tratamento testemunha recebeu apenas este e, no caso das doses de lodo de esgoto, como se considerou 1/3 do nitrogênio disponível, a menor dose (55,0 Mg.ha-1 $)$ necessitou de maior suplementação de adubo mineral, o que explica a semelhança nos resultados obtidos em relação à testemunha.

Já os valores de nitrogênio encontrados nas folhas diagnose (Figura 2) indicam, além de um consumo de luxo que pode provocar competição com outros nutrientes, também o excesso de nitrogênio disponível, fonte de contaminação dos lençóis freáticos.

O excesso do nitrogênio proporciona ainda, aumento no custo de produção. Machado (1997) afirma que 40\% dos gastos com a cultura são referentes à adubação nitrogenada. Desta forma, a correta utilização de um resíduo pode reduzir os riscos de contaminação ao ambiente e ainda proporcionar maior competitividade de mercado ao produtor

\section{Conclusão}

A concentração de nitrogênio em planta inteira, folha diagnose e grão de milho não foi influenciada pelos tratamentos. As maiores doses de lodo de esgoto proporcionaram maiores quantidades de nitrogênio no solo.

O nitrogênio do solo, após a profundidade de 0,6 m, não diferiu entre as camadas avaliadas.

Quanto maior a dose de lodo de esgoto, menor a proporção de nitrogênio em profundidade dentro de cada tratamento.

\section{Referências}

ANDRASKI, T.W.; BUNDY, L.G; BRYE, K.R. (2000) Crop management and corn nitrogen rate effects on nitrate leaching. Journal of Environmental Quality, v. 29, n. 4, p. 1095-1103.

ARAÚJO, P.P.; OLIVEIRA, F.A.; CAVALCANTE, I.N.; QUEIROZ, J.C.B.; CARNEIRO, B.S.; TANCREDI, A.C.F.N.S. (2011) Classificação hidroquímica e contaminação por nitrato no aquífero livre Barreiras na bacia do rio Capitão Pocinho região do médio rio Guamá na Amazônia oriental. Revista Ambiente \& Água, v. 6, n. 2, p. 266-281.

BETTIOL, W. \& CAMARGO, O.A. (2007) Lodo de esgoto na agricultura: potencial de uso e problemas. Disponível em: www.cnpma.embrapa. br. Acesso em: 26 jul. 2007.

BINDER, D.L.; DOBERMANN, A.; SANDER, D.H.; CASSMAN, K.G. (2002) Biosolids as nitrogen source for irrigated maize and rainfed sorghum. Soil Science Society of American Journal, v. 66, p. 531-543.

BRASIL. Ministério do Meio Ambiente. Conselho Nacional do Meio Ambiente - CONAMA. (2006). Resolução no 375, de 29 de agosto de 2006. Disponível em: www.mma.gov.br/port/conama/res/res06/ res37506.pdf. Acesso em: 5 dez. 2007.

BRASIL. Ministério da Agricultura, Pecuária e Abastecimento. Empresa Brasileira de Pesquisa Agropecuária - EMBRAPA. (2006) Sistema Brasileiro de Classificação de Solos. 2 ed. Rio de Janeiro. Embrapa Solos, 306 p.

BROUSSARD, W. \& TURNER R.E. (2009) A century of changing landuse and water-quality relationships in the continental US. Frontiers in Ecology and the Environment, v. 7, p. 302-307.
CERETTA, C.A \& FRIES, M.R. (1997) Adubação nitrogenada no sistema de plantio direto. In: NUERNBERG, N.J. Plantio direto: conceitos, fundamentos e práticas culturais. Lages Sociedade Brasileira de Ciência do Solo, Núcleo Regional Sul, p. 111-120.

EPSTEIN, E. \& BLOOM, A.J. (2004) Mineral nutrition of plants: principles and perspectives. 2 ed. Sunderland. Sinauer Associates, $380 \mathrm{p}$.

FABIANOVICZ, R. \& SILVA JR G.C. (2007) Legislação e políticas de proteção de águas subterrâneas nos cenários nacional e internacional: tendências e resultados práticos. Geociências, v. 26 , n. 1, p. 7-16.

HANSEN, B.; KRISTENSEN, E.S.; GRANT, R.; HØGH-JENSEN, H.; SIMMELSGAARD, S.E.; OLESEN, J.E. (2000) Nitrogen leaching from conventional versus organic farming systems - a systems modeling approach. European Journal of Agronomy, v. 13, p. 65-82.

MACHADO, A.T. (1997) Perspectiva do melhoramento genético em milho (Zea mays L.) visando eficiência na utilização do nitrogênio. 1997. 219 f Tese (doutorado em Agronomia) - Universidade Federal Rural do Rio de Janeiro, Rio de Janeiro.

MALAVOLTA, E. (2006). Manual de nutrição mineral de plantas. São Paulo. Editora Agronômica Ceres, 631 p.

MALAVOLTA, E.; VITTI, G.C.; OLIVEIRA, S.A. (1997) Avaliação do estado nutricional das plantas: princípios e aplicações. 2 ed. Piracicaba. Piracicaba Potafos, $319 \mathrm{p}$. 
MANTOVANI, A.; ERNANI, P.R.; SANGOI, L. (2007). Adição de superfosfato triplo e a percolação de nitrogênio no solo. Revista Brasileira de Ciências do Solo, v. 31, n. 5, p. 887-895.

MELO, W.J. (1974) Variação do N-amoniacal e N-nítrico em um Latossolo Roxo cultivado com milho (Zea mays L.) e com lablab (Dolichos lablab L.). 1974. 104 f. Tese (doutorado em Solos e Nutrição de Plantas) - Escola Superior de Agricultura "Luiz de Queiroz" Universidade de São Paulo, Piracicaba.

OLIVEIRA, F.C.; MATTIAZZO, M.E.; MARCIANO, C.R.; MORAES, S.O. (2001) Lixiviação de nitrato em um Latossolo amarelo distrófico tratado com lodo de esgoto e cultivado com cana-de-açúcar. Scientia Agricola, v. 58, n. 1, p. $171-180$

PAULA, R.A.; CORRÊA, R.S; COTTA, T.P. (2011) Lixiviação de nitrato de um substrato minerado tratado com lodo de esgoto doméstico. Bragantia, v. 70, n. 1, p. 104-112

PIOVESAN, R.P.; FAVARETTO, N.; PAULETTI, V.; MOTTA, A.C.V.; REISSMANN, C.B. (2009) Perdas de nutrientes via subsuperfície em colunas de solo sob fertilização mineral e orgânica. Revista Brasileira de Ciência do Solo, v. 33, n. 4, p. 757-766.
RAIJ, B. van; ANDRADE, J.C.; CANTARELLA, H.; QUAGGIO, J.A. (2001) Análises químicas para avaliação da fertilidade de solos tropicais. Campinas. Instituto Agronômico, 285 p.

RAIJ, B. van \& CANTARELLA, H. (1997) Milho. In: RAIJ, B. van; CANTARELLA, H.; QUAGGIO, J.A.; FURLANI, A.M.C. Recomendações de adubação e calagem para o Estado de São Paulo. 2 ed. Campinas. Instituto Agronômico, p. 56-59. (Boletim Técnico, 100).

RAUN, W.R. \& JOHNSON, G.V. (1999) Improving nitrogen use efficiency for cereal production. Agronomy Journal, v. 91, n. 3, p. 357-363.

SILVA, F.A.S. \& AZEVEDO, C.A.V. (2002) Versão do programa computacional Assistat para o sistema operacional Windows. Revista Brasileira de Produtos Agroindustriais, v. 4, p. 71-78.

STINTZING, A.R. \& SALOMON, E. (2002) Application of broiler chicken manure to lettuce and cabbage crops. Effect on yield, plant nutrient utilisation and mineral nitrogen in soil. Acta Horticulturae, n. 571. p. 119-126.

WARD, M.H.; RUSIECKI, J.A.; LYNCH, C.F.; CANTOR, K.P. (2007) Nitrate in public water supplies and the risk of renal cell carcinoma. Cancer Causes Control, v. 18, n. 10, p. 1141-1151. 